Muséologies

Les cahiers d'études supérieures

muséologies

\title{
Project Anywhere: The challenge of evaluating and disseminating art and artistic research outside traditional exhibition environments
}

\section{Sean Lowry}

Volume 8, numéro 1, 2015

Réflexions sur la pratique curatoriale et la recherche-création

URI : https://id.erudit.org/iderudit/1034609ar

DOI : https://doi.org/10.7202/1034609ar

Aller au sommaire du numéro

Éditeur(s)

Association Québécoise de Promotion des Recherches Étudiantes en Muséologie (AQPREM)

ISSN

1718-5181 (imprimé)

1929-7815 (numérique)

Découvrir la revue

Citer cet article

Lowry, S. (2015). Project Anywhere: The challenge of evaluating and disseminating art and artistic research outside traditional exhibition environments. Muséologies, 8(1), 33-52. https://doi.org/10.7202/1034609ar

Tous droits réservés (C) Association Québécoise de Promotion des Recherches Étudiantes en Muséologie (AQPREM), 2016
Ce document est protégé par la loi sur le droit d'auteur. L’utilisation des services d'Érudit (y compris la reproduction) est assujettie à sa politique d'utilisation que vous pouvez consulter en ligne.

https://apropos.erudit.org/fr/usagers/politique-dutilisation/ 
Article un

Project Anywhere: the challenge of evaluating and disseminating art and artistic research outside traditional exhibition environments

Sean Lowry 
Sean Lowry is a Sydney-based artist, musician and writer. He holds a PhD in Visual Arts from The University of Sydney and is currently Convenor of Creative and Performing Arts at the University of Newcastle, NSW, Australia. Lowry has exhibited, performed and presented artistic research internationally, and his published writing appears in numerous journals and edited volumes. Lowry is also the Founder and Executive Director of Project Anywhere: Art At The Outermost Limits Of LocationSpecificity (www.projectanywhere.net). During 2014, Lowry was Visiting Scholar/Artist at the School of Art, Media, and Technology at Parsons The New School for Design in New York.www.seanlowry.com. Sean.Lowry@ newcastle.edu.au and theseanlowry@gmail.com 


\section{Introduction}

Much contemporary artistic activity and research is now conducted and understood in relation to an expanded realm of spaces, contexts and locations beyond traditional museum and gallery environments. Although the term "expanded field" ${ }^{1}$ was first coined by Rosalind Krauss in 1979 to attempt to account for various mixed media installation practices, architectural incursions and land art projects still being described as "sculpture," the term was later extended to encapsulate everything from painting to cinema, music and architecture. For Miwon Kwon in 1997, an expanded understanding of spaces and places of art now also includes the social, political and economic spheres of everyday life. ${ }^{2}$ Moreover, much of this expanded practice is specifically concerned with critiquing or rethinking traditional exhibition circuits. Meanwhile, although artistic activity and research of this kind has grown enormously in recent decades, institutional approaches to validation and dissemination remain largely dominated by traditional approaches to exhibition location and duration. With much of this artistic activity "dematerialised," ${ }^{3}$ insofar as it is often more concerned with events, actions or processes than with the production of discrete objects to be displayed in museums and galleries, it invariably demands a supplementary contextual framework in order to be meaningfully recognized as art .

This paper assumes a definition of research ${ }^{4}$ in which artistic practice is a significant medium that is not founded upon definitions of research commonly found in the sciences ${ }^{5}$. This approach to research is both widely

1 The term expanded field was coined by Rosalind Krauss in: KRAUSS, R. "Sculpture in the expanded field" October, Vol. 8 Spring 1979 , pp. 30-44.

2 For the purposes of this article, this idea was extended to include social, political and economic spheres of everyday life by Miwon Kwon in: KWON, M. "One place after another: notes on site specificity” October, vol. 80 (Spring 1997), pp. $85-110$.

3 The term dematerialization was coined and by Lucy Lippard and John Chandler in 1968. See: LIPPARD, L. Six years: the dematerialization of the art object 1966-1972, New York: Praeger, 1973. contested and often regarded as problematic in terms of establishing a consistent approach to its institutional validation. The challenges facing artist academics wishing to produce, validate and disseminate artistic research are already varied and complex under relatively stable conditions within traditional museum and gallery environments. These complexities are of course considerably exacerbated once the focus of artistic activity is shifted to locations and contexts located outside of traditional exhibition contexts such as museums and galleries. This paper is concerned with three key challenges facing artist academics working in expanded exhibition formats. The first challenge is something that potentially impacts all research in which artistic practice is the significant medium: the problem of institutional validation in a form that can be considered commensurate with the journal-based paradigm typically recognised by universities and other institutional bodies that value the quality of research outputs. The second key challenge is also something that also broadly impacts the meritocratic currency of artistic research: the relatively undemocratic role of the curator as a "cultural gate-keeper." The third challenge is something that more specifically impacts artists and researchers working in expanded fields of artistic activity: the restrictive and prescriptive limitations of location and time specificity typically demanded by traditional museum and gallery exhibition venues and programming.

The problem of institutionally validating research in which artistic practice is the significant medium is considerably more difficult whenever that activity is not to contained or

4 Research is defined as "the creation of new knowledge and/or the application of existing knowledge so as to generate new concepts, methodologies and understandings". See "Evaluation criteria" Project anywhere: art at the outermost limits of location-specificity, http://www.projectanywhere.net/ peer-review/ (retrieved 06/10/2014).

5 Positivist science holds several basic beliefs about the nature of knowledge, which together form positivist epistemology - the cornerstone of the quantitative paradigm. With the relatively recent integration of artistic disciplines within universities, artists have been challenged to review their practices in academic terms. Artistic research invariably challenges epistemological assumptions and established procedures for producing knowledges. 
presented within a traditional exhibition space such as a museum or gallery. Project Anywhere is offered as a possible solution to meeting these three aforementioned and interrelated challenges. Conceived and established by the author in 2012, Project Anywhere is an "expanded exhibition model encompassing the entire globe in which the role of curator is replaced with the type of peer review model typically endorsed by a refereed journal.” ${ }^{6}$ Specifically emphasizing artistic activity and "research undertaken outside conventional exhibition contexts," Project Anywhere is “dedicated to the evaluation and dissemination of art at the outermost limits of location-specificity [and] endorses a rigorous peer review process for assessing the quality of artistic research outcomes"”.

It is important to stress that Project Anywhere is not an online gallery. In asserting that the exhibited art and research itself is not on the website, it becomes clear that the exhibited art and artistic research must be apprehended as existing elsewhere in space and time. Yet as noted by Project Anywhere Editorial and Advisory Committee ${ }^{8}$ member Ilmar Taimre, this insistence is a necessary but insufficient criterion for unambiguously defining the core character of Project Anywhere as an exhibition model. For Taimre, a useful way of addressing this distinction is found in the theoretical framework of philosopher and artist Jeffrey Strayer. Taimre's interpretation ${ }^{9}$ of Strayer's formulation of art at the "limits

6 Project anywhere: art at the outermost limits of location specificity, http://projectanywhere.net (retrieved 06/10/2014). 7 Ibid.

8 Project Anywhere Committee http://www.projectanywhere.net/steering-committee/ (retrieved 06/10/2014). Founder and Executive Director: Dr. Sean Lowry, The University of Newcastle. Editorial Committee: Professor Brad Buckley, Professor of Contemporary Art and Culture, The University of Sydney; Professor Bruce Barber, Chair of Media Arts, Nova Scotia College of Art and Design; Associate Professor Simone Douglas, Director, MFA Fine Arts, Parsons The New School for Design; Professor Steve Dutton, Professor in Contemporary Art Practice, The School of Art and Design, College of Arts, The University of Lincoln; Dr. Angela Philp, The University of Newcastle. Dr. Adam Geczy, The University of Sydney. Dr. Les Joynes, Director, FormLAB and Visiting Associate Professor of Art, Renmin University of China. Advisory Committee: Prof. Su Baker, Director, VCA, University of Melbourne; Ilmar of abstraction" ${ }^{10}$ is a key foundational aspect for Project Anywhere. For Strayer, even art at the outermost limits of conceptual abstraction ultimately depends on the existence of at least one "public perceptual object" on which a subject's understanding of the intended identity of an artwork depends ${ }^{11}$. This "public perceptual object" can assume the form of anything from a physical artefact to a performed gesture, a text, a site, or even an imagined or virtual object. It is, in the words of Canadian philosopher David Davies, simply the "vehicular medium" through which an "artistic statement is articulated." ${ }^{12}$ Building on this idea, it is suggested that the Project Anywhere website acts as an indexical device or "public perceptual object" essential to establishing the intended identity of art and research located elsewhere (and potentially anywhere) in time and space.

After contextualizing and discussing the three challenges mentioned previously, this paper will examine the operation and limitations of Project Anywhere's blind peer evaluation model. Referencing internal documents ${ }^{13}$ populated by Project Anywhere's international community of blind peer reviewers, all of which are artist academics of international standing, this paper will discuss the challenge of meaningfully qualifying new knowledge production in artistic activities undertaken in non-traditional exhibition environments in a manner commensurate with the expectations of clarity and relevance institutionally demanded of "research". To preserve the

Taimre, Executive Consultant, Independent Researcher/ Virtual Musician; Dr. Jocelyn McKinnon, The University of Newcastle; Associate Professor Nancy de Freitas, School of Art and Design, Auckland University of Technology.

9 TAIMRE, I. Unpublished Working Draft for PhD Dissertation, School of Creative Arts, The University of Newcastle, forthcoming.

10 STRAYER, S. Subjects and objects: art, essentialism, and abstraction (philosophy of history and culture) Brill Academic Pub, 2007), p. 3.

11 Ibid.

12 DAVIES, D. Art as Performance (Oxford: Blackwells, 2004), p. 59.

13 Although the identity of the authors of internal documents referenced in this paper are withheld, all written consents are explicitly established. Project Anywhere's archive of blind peer validations and written consents are available for external institutional auditing at any time upon request. 
requisite anonymity of Project Anywhere's evaluation system, all identifying information is omitted. ${ }^{14}$ For the purposes of illustrating the points of discussion presented in this paper, the author has selected a series of broadly representative yet non-identifiable fragments from its internal archive of blindpeer evaluations. Although finally (and perhaps unsurprisingly) an enterprise of mixed successes in terms of establishing clarity and maintaining rigor, this paper nonetheless seeks to demonstrate that initiatives such as Project Anywhere represent the beginning of an important rethinking of the way in which much contemporary art and artistic research is validated and disseminated.

\section{Historical overview: expanding fields of artistic practice}

The historical origins of the kinds of expanded artistic practices and research activities discussed in this paper are traceable primarily to the 1960s, when a new generation of artists worked to challenge the way in which viewers are involved in the conditions of art's production and reception. Picking up on ideas originating in the early twentieth century historical avant-gardes, this "second horizon" 15 of post war "neo-avant-garde" 16 artists was concerned with the creation of art experiences that both offered active viewer participation and challenged traditional limitations for exhibition and display. Significantly, the outcomes of these activities were typically not discrete objects designed for museological display but rather ephemerally framed or performed actions and experiences that aimed to problematize established distinctions between art and non-art.

14 All reviews are numbered in accordance with Project Anywhere's internal systems and available (together with explicit written consents) for independent auditing and institutional verification upon request.

15 BÜRGER, P. Theory of the avant-garde trans. SHAW, M. Minneapolis: University of Minnesota Press, 1984.

16 FOSTER, H. The return of the real, Cambridge, Mass: MIT Press, 1996, p. xi.

17 KWON, M. "One place after another: notes on site specificity” October, Vol. 80 (Spring 1997), p. 91.
With public perception of aesthetic experience transformed from passive to active, and the conditions of artistic production and dissemination a growing field critique, the stage was set for ever more radical challenges to the specificities of space, place, time and institutional boundaries in established exhibition practices. For Miwon Kwon, this radical rethinking of art's contextual parameters constitutes an "epistemological challenge to relocate meaning from within the art object to the contingencies of its context" ${ }^{17}$. In the academic environment in which many artists are working today following the assimilation of art schools within universities, this contested terrain and its inherent defiance of traditional exhibition circuits presents a new series of challenges. Significantly, because this kind of work is characteristically discursive and deliberately ambiguous, it also functions to problematize established academic expectations.

Clearly, within this "expanded field", it is no longer realistic to expect all art and artistic research to fit within the physical and material constraints of traditional museum and gallery spaces. Although some artist academics have positioned work to either function within or directly critique traditional institutional spaces, others are simply unable to effectively utilize traditional spaces. In many and differing ways, many artist academics have abjured traditional exhibition environments in favour of new dynamic and ever expanding formats. From social dinner party events" ${ }^{18}$ to walking performances in wilderness areas ${ }^{19}$ to modular eco structures in remote communities ${ }^{20}$, these practices radically problematize established processes of academic validation insofar as they can invariably make direct access and

18 See for example: RYAN, S. "Silent dinner party" Project anywhere: art at the outermost limits of location-specificity, 2012. http://projectanywhere.net/archived/silent-dinnerparty (retrieved 06/10/2014).

19 See for example: SHORTER, M. "Schleimgurgeln: song for Glover" Project anywhere: art at the outermost limits of location specificity, 2012, http://projectanywhere.net/archived/ schleimgurgeln-song-for-glover (retrieved 06/10/2014). 20 See for example: KALLIWODA, H. "WiaS (The world in a shell)" Project anywhere: art at the outermost limits of location-specificity, 2012, http://projectanywhere.net/project/ wias (retrieved 06/10/2014). 
verification challenging. Consequently, artists and researchers that produce work that explicitly tests the limits of location-specificity are not availed quality assurance processes that typically define value within the academy.

\section{Demands and limitations: the challenge of institutionally validating research in which artistic practice is the significant medium}

Research is broadly understood as the study of phenomena, finding solutions to problems, analyzing issues, and reviewing or synthesizing existing knowledge. Two key philosophical traditions concerning the source of new knowledge are empiricism, which holds that our knowledge is primarily derived from sense experience or observation, and rationalismwhich holds that knowledge is primarily based in reason. The use of established research methodologies is generally regarded as assisting in the task of framing an inquiry and understanding the research process. Although there are many and varied research methodologies applied in the pursuit of new knowledge, the use of the written word remains central to this task. Given that the whole idea of evaluating academic research is founded upon principles more typical to science, research in which artistic practice is the significant medium is characterized as non-traditional, and consequently does not attract levels of funding open to traditional research. For Adam Geczy, "[c] aught in this condescending bind, in order to leverage income, art schools find themselves in the quandary where they need to support forms of research that they can justify, that is, which can be rationalized"21. Typical criticisms (from a classic scientific perspective) of artistic method focus on its lack of objectivity and the idiosyncratic nature of creative works as lacking rigour ${ }^{22}$. For Geczy, although the idea of new knowledge is "fairly easy to understand when it comes to science [...] and the humanities," ${ }^{23}$ given that art "is unique from the very beginning," the uncomfortable question as to "whether it is new knowledge" often defaults to the question as to "whether the art is "good". ${ }^{24}$ Moreover, he warns, before we get "ahead of ourselves, we need to ask whether art ever deals in new knowledge at all, or simply reasserts fundamentals about existence." ${ }^{25}$ It is for this reason that it is fundamentally important to distinguish "art" as a realm of human cultural experience in its own right from its supplementary role as a vehicle for the apprehending ideas presented as "research". In this sense we might reasonably suggest (depending of course upon both the nature of the work and the context of its presentation) that both "good" and "bad" art both can and cannot necessarily perform the supplementary role of constituting a vehicle for "research."

Challenging conventional epistemological assumptions, the last two decades have seen a more concerted push to recognise research that involves artistic production as a legitimate paradigm alongside quantitative and qualitative approaches. Moreover, with the broader integration of arts schools within universities, artist academics are increasingly expected to review their creative work in academic terms. Although there is some limited institutional acknowledgement that art may "speak for itself" in certain ways, and that new knowledge is produced through the materiality of the work itself, there is a larger general consensus that the production of creative artefacts (objects or processes) as a research endeavour should be accompanied by some form of written exegetical or theoretically contextualizing scholarly text. A key feature that research in which artistic practice is the significant medium embodies is the assertion that certain ideas are given
21 GECZY, A. "The new textuality for the visual arts: entrenchment in the academy" Broadsheet: contemporary visual art + culture, vol. 43.3, 2014, p. 69.

22 GRAY, C. and MARLINS, J. Research procedures/methodology for artists and designers, 1993, http://design.osu.edu/ carlson/id785/epgad-highlighted.pdf (retrieved 06/10/2014).
23 GECZY, A. "The new textuality for the visual arts: entrenchment in the academy" Broadsheet: contemporary visual art + culture, vol. 43.3, 2014, p. 69.

24 Ibid.

25 Ibid. 
form through processes of making and doing ${ }^{26}$ Also, as put by Shaun McNiff in 1998, one often "cannot define the final outcome" of artistic production in advance, for in many cases "the examination of meaning [occurs] through the process of creative expression", and consequently, "the most meaningful insights [can] often come by surprise" ${ }^{27}$. Accordingly, a defining feature of much phenomenological research in which artistic practice is the significant medium is a lack of a prescriptive predetermined picture. In other words, for supporters of this view, the final form of that new knowledge emerges in the doing. Another variation of this argument holds that artists bring a capacity to view things from a variety of perspectives through this focus upon generative processes. For Aitchison, et al. in 2004, for example, artists advance understanding through recontextualizing the familiar and introducing new ways of seeing, thinking and knowing ${ }^{28}$. At any rate, the nature of "process" in research in which artistic practice is the significant medium is inherently fuzzy. Roundly put, it is apparent that key points of difference within the experience of producing and perceiving art (and by extension much activity across the broader humanities) are both frustratingly and fascinatingly incompatible with the whole idea of research, and by extension, the expectations of the academy. As recently noted by Michael Schwab, the Editorin-Chief for the Journal for Artistic Research (JAR), there is an institutional "tendency to believe that a research process starts with a set of questions to which over time answers are given." ${ }^{29}$ By contrast, Schwab proposes a thought experiment in which we might imagine the possibility of an artist presenting

26 For Rebecca Fortnum and Elizabeth Fisher "artists often begin something without knowing how it will turn out.” FISHER, E (Editor), FORTNUM, R (Editor). On not knowing: how artists think, "preface", Black Dog Publishing, 2014. For Adam Geczy, "[i]n practice, this translates as thinking through doing". GECZY, A. "The new textuality for the visual arts: entrenchment in the academy," Broadsheet: contemporary visual art + culture", vol. 43.3, 2014, p. 70 . 27 MCNIFF, S. Art-based research, London; Philadelphia: Jessica Kingsley Publishers, 1998, p. 40.

28 AITCHISON, C. BOLT, B. CARSON, S. INGS, W. HAMILTON, J \& J HARLEY, R. The emergent field of creative practice/practice-led/practice-based research, "research while avoiding results." ${ }^{30}$ First he notes that the use of the word "project" in the arts is widely used "to indicate that one is captured by a particular issue and that a sustained relationship with this issue has been entered," and that some of these projects then "slip into" being institutionally defined as "projects." ${ }^{11}$ Schwab then presents this thought experiment as challenge to the task of "deciding how much or how little process should matter in a research publication." ${ }^{32}$ Significantly, this kind of thinking represents the speculative edges of rethinking the nature of research in which artistic practice is the significant medium. There is still much work to do before ideas such as these are broadly institutionally recognized.

Although heavily contested, the most widely used term for creative arts inquiry remains practice-based research. Practice-based research is broadly understood as an original investigation undertaken in order to produce new knowledge, at least partly by means of creative practice and the outcomes of that practice. Accordingly, claims to originality and knowledge are typically demonstrated through creative outcomes, either via direct experience or via artefacts or via substantial documentation. Other widely used terms include practice-led research, practice-centred research, and artistic research. For Robin Nelson, perhaps "it is time to speak less of practice-as-research and to speak instead of arts research (a significant methodology of which just happens to be based in practices)." ${ }^{33}$ Common within all of these variations is the notion, despite the fact that the significance and context of research claims might still be described in words, that a full understanding is only accessible via direct

http://supervisioncreativeartsphd.net/wp-content/ uploads/2013/12/3.1-Literature-Review1.pdf (retrieved $06 / 10 / 2014)$

29 SCHWAB, M. "Editorial" The journal for artistic research, Issue 6, http://www.jar-online.net/index.php/issues/ editorial/488 (retrieved 06/10/2014).

30 Ibid.

31 Ibid.

32 Ibid.

33 NELSON, R. "Practice-as-research and the problem of knowledge” Performance Research, vol. 11, no. 4, pp. 116. 
reference to or experience of the creative outcomes. For some, however, these terms are limited and increasingly problematic. Brad Buckley and John Conomos, for example, argue against the use of terms such as "practice based." ${ }^{34}$ For Buckley and Conomous, there is a need to move beyond these terms, together with descriptors such as non-traditional research outputs, towards the adoption of a more "mature" position. As seconded by Geczy, the very use of the term "non-traditional" is a "way of undermining research without risking too much offence."35

Although language is clearly a fundamental tool for delineating power, it is of course potentially contradictory to simultaneously argue for key points of difference characterized by this kind of research whilst maintaining that it be simply considered part of and commensurate with a broader and established research culture. For some the choice is between extending and establishing traditions. Given that "art and design schools have now been part of universities for several decades," as Buckley and Conomos have also argued, perhaps the question that we really should be asking is how long does it take for this type of research to become a tradition? ${ }^{36}$ Finally, as a consequence of a robust discussion initiated by Buckley ${ }^{37}$ between Project Anywhere Editorial and Advisory Committee members over several days in early December 2014, ${ }^{38}$ it was finally broadly agreed that the potentially "apologetic 'practice-based' prefix" should be officially dropped by Project Anywhere. As Buckley put it, it was agreed that in this instance, "to name is to indicate something that is less." 39

34 BUCKLEY, B (Editor) and CONOMOS, J (Editor). Rethinking the contemporary art school: the artist, the PhD, and the academy, Press of the Nova Scotia College of Art and Design, 2010.

35 GECZY, A. "The new textuality for the visual arts: entrenchment in the academy" Broadsheet: contemporary visual art + culture", vol. 43.3, 2014, p. 69.

36 Ibid.

37 BUCKLEY, B. Email addressed to Project Anywhere Committee (10/12/2014).

38 Email conversation between Project Anywhere Committee members (10/12/2014 -13/12/2014).
It is telling that the problem of "naming" was debated so seriously for several days by Project Anywhere's Committee. Whilst Associate Professor Nancy de Freitas from Auckland University of Technology agreed that "practice-based" should be dropped, she was particularly humored by "how many truly earnest debates took place [...] to establish which was better-practice-led or practice-based" ${ }^{40}$. It is however also worth conceding, as de Freitas notes, that certain "locator" words such as "artistic" or "design" do not necessarily contain an apology, for they function "like climate research or medical research etc" ${ }^{41}$. Interestingly for de Freitas (in pointing to a potentially untranslatable quality), "the Canadian term recherche-création possibly contains greater nuance" ${ }^{42}$. Professor Bruce Barber from Nova Scotia College of Art and Design agreed, seeing this as an "endorsement of research creation which is the title of a graduate level methodology course $[\ldots]$ at NSCAD." ${ }^{43}$ Barber also pointed to the potential value of the keyword "praxis" and its broader understanding as a "conflation or art, theory, research and practice." ${ }^{44}$ Meanwhile, Associate Professor Simone Douglas of Parsons The New School for Design suggested that we adopt the simpler term "art research." ${ }^{35}$ At this point, de Freitas quickly responded, pointing out that "the term art research has always had a connection to research about art", whereas the "term currently in use in Europe for research that involves making is artistic research. ${ }^{46}$ At this juncture, Professor Steve Dutton of The University of Lincoln suggested that although the term "artistic research" is preferable to "practice-based research", the semantic nature of the discussion probably added up to a reasonable argument for broadly

39 Ibid.

40 DE FREITAS, N. Email addressed to Project Anywhere Committee (11/12/2014).

41 Ibid.

42 Ibid.

43 BARBER, B. Email addressed to Project Anywhere Committee (12/12/2014).

44 Ibid.

45 DOUGLAS, S. Email addressed to Project Anywhere Committee (12/12/2014).

46 DE FREITAS, N. Email addressed to Project Anywhere Committee (12/12/2014). 
accepting Buckley's charge that we should be "mature enough to accept what we do [is] research $[\ldots]$ especially in a project of such global reach". ${ }^{47}$ As Geczy puts it, "[t]he list of qualifiers has a motive of describing, while tacitly undermining; the need for a qualifier" ${ }^{* 8}$. Project Anywhere has endorsed the use of the term "research" in all promotional materials since late 2014.

Although there is clearly a lack of consensus around key terminologies, and much debate around what this type of research finally entails, there is perhaps broader agreement around base definitions. In principle, we are talking about a research methodology that refers to the work of art or process of art making as a form of research and to the creation of art as something capable of generating insights that might then be documented, theorised and generalised ${ }^{49}$. The research component of research undertaken by artists is, in some respects, comparable with any definition of research, a key element of which is the transferability of the understandings reached as a result of the research process. The nature of and vehicle through which this transferability of understandings are finally presented and disseminated is however broadly contested.

\section{The problem of curator as "cultural gate-keeper"}

Curators not only select artists and artworks but ultimately play a substantial role in shaping how these works are disseminated and interpreted through the production of paratextual materials such as catalogues, wall texts, and press releases. Although paratextual materials such as wall texts are also developed by educators in some progressive museums, it is

47 DUTTON, S. Email addressed to Project Anywhere Committee $(13 / 12 / 2014)$

48 GECZY, A. "The new textuality for the visual arts: entrenchment in the academy" Broadsheet: contemporary visual art + culture", vol. 43.3, 2014, p. 69.

49 SMITH, H. and DEAN, R. Practice-led research, research-led practice in the creative arts, Edinburgh: Edinburgh University Press). 2009, p. 7. nonetheless clearly apparent that many curators wield substantial power in terms of determining that which will be included or excluded for serious consideration as art-and by extension, research. Several recent books have sought to rethink and retool the idea of curating in keeping with the aforementioned expansion of exhibition formats. Beryl Graham and Sarah Cook's 2014 book Rethinking curating ${ }^{50}$, for example, explores modes of curating beyond traditional museum formats such as publishing, broadcasting, festivals, laboratory work, the employment of distributive and participatory systems, and web-based contexts for collaboration and social networking. In their examination of curatorial practices that are difficult to classify according to traditional museological categories such as medium, geography or chronology, Graham and Cook argue that curators must now adapt to more contemporary concerns such as immateriality, the questioning of time and space, social engagement, and performativity.

Meanwhile, other voices are calling for a whole41 sale rethinking of the role of the curator. In a forthcoming publication, for example, Maura Reilly employs the term "curatorial activism" ${ }^{1}$ to address a perceived need for new curatorial strategies that provide alternatives to exclusionary models for collection and display. For Reilly, the term refers to the practice of organizing exhibitions with the principal aim of giving voice to artists excluded within traditional curatorial strategies and museum formats. In another example of developments that push against established systems of curatorial selection, New York based apexart ${ }^{52}$ promotes an annual "Unsolicited Proposal Program" that "uses democratic processes" 53 to select part of its exhibition program. Within this initiative, artists are invited to "[s]ubmit a proposal

50 GRAHAM, B. and COOK, S. Rethinking curating, Cambridge, Mass: MIT Press, 2010.

51 See REILLY, M. Curatorial activism: toward an ethics of curating, Charta, forthcoming 2015.

52 apexart, 291 Church Street, New York, NY 10013, http://www.apexart.org (retrieved 06/10/2014). 53 "apexart: Unsolicited proposal program, October 1November 1, 2014" e-flux email announcement, September 29, 2014. 
for an idea-driven group exhibition [of] up to 500 words" without any images or links to "an international jury of over 100 creative professionals who vote on submissions online" using a "custom-made computer script" to crowd source votes and select the three proposals that "received the highest scores." ${ }^{54}$ All three winners then "receive financial and administrative support from apexart to mount their exhibitions in [the] Manhattan space." ${ }^{55}$

Germane to Project Anywhere's philosophy is the value of overcoming the relatively undemocratic traditional role of the art curator as "cultural gate keeper." ${ }^{" 6}$ For Project Anywhere, the challenge of exhibiting and disseminating research that results from a creative process could only be meaningfully analogized with refereed "publishing" if the figure of curator was substituted for a democratizing peer evaluation system. As noted by Buckley in another publication co-authored with John Conomos, despite a proliferation of critical education in the curatorial and museum studies, contemporary institutions are nonetheless heavily influenced by an "ascendancy of a corporate managerialism in determining the curator's modus operandi and raison d'être. ${ }^{57}$ Also, as noted by Paul O'Neill in his 2012 book The culture of curating and the curating of culture(s), the role of curator has shifted during the last 25 years from that of a "behind-the-scenes" caretaker of collections to a highly "visible, centrally important cultural producer" and critically significant "auteur" ${ }^{58}$. Meanwhile, despite a subsequent "blurring the distinction between artist and curator" 59 , a key aspect of this relationship from the perspective of artists and academics remains that of a disproportioned power in the hands of the curator as gatekeeper. For Buckley and Conomos, the key

54 Ibid.

55 Ibid.

56 Project anywhere: art at the outermost limits of

location-specificity, http://projectanywhere.net (retrieved 06/10/2014).

57 BUCKLEY, B. and CONOMOS, J. "The delinquent curator: or how curators shafted Australian art" Broadsheet: contemporary visual art + culture, vol. 41.1, 2012, p. 46. 58 O'NEILL, P. The culture of curating and the curating of culture(s) Cambridge, Mass: MIT Press, 2012. question becomes how art is "experienced directly by the spectator in a society $[. .$. heavily laminated by cultural, museological and tertiary educational structures, agendas and self-interest groups all vying to produce normative ideas, contexts and values for the making, exhibiting and manifestation of art." ${ }^{00}$ Consequently, they ask whether "art needs "mediation by a museum, gallery or a curator?” ${ }^{61}$ Project Anywhere's response to this question is resoundingly in the negative.

\section{Developing a peer evaluation model}

Common barriers that separate research in which artistic practice is the significant medium from traditional research include approaches to analysis, documentation and display. Problematizing this disjuncture further is the added challenge of adequately documenting geographically remote or ephemeral contemporary artistic research in a format that can facilitate meaningful dialogue under relatively stable conditions, especially given that much art and research in which artistic practice is the significant medium is framed in relationship with specific formal, architectural, historical or symbolic languages within a host context. In response to challenges already outlined that face artists working in expanded fields of activity and at the outermost limits of location-specificity, Project Anywhere was presented as a possible solution to the challenge of disseminating art outside traditional exhibitions environments such as museums and galleries. Promoting "research undertaken outside conventional exhibition contexts, Project Anywhere is specifically dedicated to the evaluation and dissemination of art at the outermost limits of location-specificity." ${ }^{2}$

59 Ibid.

60 BUCKLEY, B. and CONOMOS, J. "The delinquent curator: or how curators shafted Australian art" Broadsheet: contemporary visual art + culture, vol. 41.1, 2012, p. 46. 61 Ibid.

62 Project anywhere: art at the outermost limits of location-specificity, http://projectanywhere.net (retrieved 06/10/2014). 
Following the author's original 2011 concept for a peer reviewed platform for art and artistic research outside traditional exhibition contexts, a Steering Committee was formed in $2012^{63}$ with a view to developing specific evaluation criteria. Following much debate, a two-stage peer review process was developed. It was then determined that a blind peer review of project proposals would be used to determine which projects would be hosted, whereas an open peer review of project outcomes would be better suited to the task of evaluating final outcomes. Throughout the process, it was broadly agreed that the decision to invite artist academics (as opposed to academics per se) would make it more likely that the review process would remain open to potentially emphasizing the value of artistic ideas over written ideas (and the challenge of meaningfully distinguishing same).

\section{Evaluation criteria}

After considerable debate and fine-tuning, it was eventually agreed in mid 2012 that Project Anywhere would endorse the following criteria for blind peer evaluation:

\section{Evaluation criteria for proposals:}

1. The proposed project is identifiable with following definition of research: Research is defined as the creation of new knowledge and/ or the application of existing knowledge so as to generate new concepts, methodologies and understandings.

2. The proposal makes a clear and compelling claim for the project's potential to contribute to knowledge in an identified field of creative practice (the project can be speculative, experimental or discursive in

63 Project Anywhere's Steering Committee (2012): Professor Brad Buckley, Associate Dean (Research), Sydney College of the Arts, The University of Sydney, Australia; Professor Su Baker, Director, Victorian College of the Arts, Faculty of the VCA \& Music, University of Melbourne, Australia; Professor Richard Vella, Head of School, Drama, Fine Art \& Music, University of Newcastle, Australia; Dr. Sean Lowry, School of Drama, Fine Arts \& Music, The University of Newcastle, Australia; Associate Professor Nancy de Freitas, School of Art and Design, AUT University, Auckland, New Zealand; Mr. Ilmar Taimre, nature). The claim should be made in the form of a hypothesis or proposition and it should identify relevant literature and aligned creative work; it may identify the project's potential to build upon creative precedents; it may extend or contradict existing methodologies.

3. The project description is articulated clearly; ideas are comprehensible.

\section{Evaluation criteria for final project outcomes:}

1. The project's implications for its field are communicable, its research outcomes are clear, and it makes a significant contribution to knowledge.

2. The methodology is substantiated by evidential documentation and this is presented in a form that enables the dissemination of knowledge.

\section{Score:}

After writing each project evaluation, our blind peer reviewers (all of which are artist academics of international standing) are asked to provide a score. These scores are tallied to produce our final project rankings. 1. Reject: Proposal/project inappropriate or has little merit.

2. Probable reject: Basic flaws in content or very poorly presented.

3. Marginal tend to reject: Not significantly flawed; major effort necessary to make acceptable.

4. Marginal tend to accept: Content has merit, but could be improved.

5. Clear accept: Project meets evaluation criteria; improvements may be advisable but acceptable as is.

Executive Consultant, Independent Researcher/Virtual Musician, Brisbane, Australia. Dr. Jocelyn McKinnon, School of Drama, Fine Arts \& Music, The University of Newcastle, Australia; Dr. Andre Brodyk, School of Drama, Fine Arts \& Music, The University of Newcastle, Australia; Dr. Angela Philp, Deputy Head of School—Research, Drama, Fine Arts \& Music, The University of Newcastle, Australia; Dr. Tony Schwensen, School of the Museum of Fine Arts, Boston, U.S.A. 
6. Must Accept: Outstanding proposal/ project. Suggested improvements still appropriate. ${ }^{64}$

With the evaluation criteria established and published on the Project Anywhere website in mid 2012, an Editorial Committee ${ }^{65}$ was formed in late 2012 to review proposals that had successfully navigated the peer evaluation process and approve final projects for hosting. Meanwhile, an Advisory Committee ${ }^{66}$ was formed to oversee strategic direction. It was also then agreed that Project Anywhere "does not provide funding or expect exclusivity but is instead designed to suit artist academics working anywhere in the world that are seeking independent peer-validation and international dissemination for their research." ${ }^{67}$ It was also decreed that Project Anywhere "welcomes collaborative projects and projects hosted by other institutions and museums that are seeking peer-validation" ${ }^{68}$. Project Anywhere has subsequently accepted 67 international proposals. With three to five projects selected each year, Project Anywhere is clearly competitive. To date, no hosted projects have successfully navigated the second level of peer evaluation.

This blind peer evaluation process has also resulted in an additional series of outcomes. On November 13 and 14, 2014, the author and Associate Professor Simone Douglas organized and successfully delivered the broadly attended international conference event Art \& research at the outermost limits

64 "Evaluation criteria" Project anywhere: art at the outermost limits of location-specificity,http://www.projectanywhere. net/peer-review/ (retrieved 06/10/2014).

65 Project Anywhere's current Editorial Committee: Professor Brad Buckley, Professor of Contemporary Art and Culture, The University of Sydney; Professor Bruce Barber, Chair, Media Arts Division, NSCAD University; Associate Professor Simone Douglas, Director MFA Fine Arts, Parsons The New School for Design; Professor Steve Dutton, Professor in Contemporary Art Practice, The University of Lincoln; Dr. Angela Philp, School of Creative Arts, The University of Newcastle; Dr. Adam Geczy, The University of Sydney; Dr. Les Joynes, Director, FormLAB and Visiting Associate Professor of Art, Renmin University of China. http://www.projectanywhere.net/steering-committee/ (retrieved 07/03/2015). of location-specificity at Parsons The New School for Design in New York. Together with a selection of invited guest presenters, this event featured presentations from eleven projects that had successfully navigated blind peer evaluation at the proposal stage within Project Anywhere's 2013 and 2014 programs. Together with the challenge of producing and disseminating art and research outside traditional circuits, a key theme within this conference event was the problem of defining and substantiating research "outcomes" in the fields of the visual arts, design and performance. As part of the broader discussion, some presenters also explored the relative values of direct sense experience and exegetical and paratextual elements within the formation of artistic research. For Session 1 Chair Radhika Subramaniam in particular, the experiential value of the "witness account" offered an agency potentially absent in more traditional forms of project documentation. ${ }^{69}$ Given the inherently porous and discursive nature of much artistic research, another key issue that was broadly discussed (with no clear resolution) was the challenge of establishing evaluative criteria that could be meaningfully applied to interdisciplinary projects that straddle aesthetic and other realms (such as science, politics, ethics and social issues).

This paper will now turn to an account and discussion of the operation and function of Project Anywhere's first level of peer evaluation ("the proposal stage").

66 Project Anywhere's current Advisory Committee: Professor Su Baker, Director Victorian College of the Arts, The University of Melbourne; Mr. Ilmar Taimre, Executive Consultant, Independent Researcher/Virtual Musician; Dr. Jocelyn McKinnon, School of Creative Arts, The University of Newcastle; Associate Professor Nancy de Freitas, Auckland University of Technology and Editor-in-Chief, Studies in Material Thinking; Professor Brad Buckley, Professor of Contemporary Art and Culture, The University of Sydney. http://www.projectanywhere.net/steering-committee/ (retrieved 07/03/2015).

67 Project anywhere: art at the outermost limits of location-specificity, http://projectanywhere.net (retrieved 06/10/2014).

$68 \mathrm{Ibid}$.

69 SUBRAMANIAM, R. "Session 1" (chair) Art \& research at the outermost limits of location-specificity (conference), Parsons The New School for Design, New York, November 13-14, 2014. 


\section{A new peer review model in action}

Once art and artistic research is exhibited or presented outside of traditional museum and gallery spaces, challenges pertinent to the specificities of context and/or location clearly become paramount. The nature and relative significance of such specificities, however, shift markedly depending upon the nature of a project. Clearly, a researcher's worldview (ontology), belief in how knowledge is produced (epistemology), specific disciplinary focus, and past experiences all bear influence upon both her paradigm choice and the ultimate choice of research methodology. Complicating the picture further, the question as to which specificities are finally brought to scrutiny within the evaluation process is also dependent upon the idiosyncrasies of each peer reviewer.

Given the broadly discursive and interdisciplinary scope of artistic research, it is perhaps unsurprising that different peer reviewers bring different understandings of the contextual parameters of artistic research to the evaluation process.Nevertheless, one issue of particular and consistent importance to most of the peer reviewers invited to participate in Project Anywhere's blind peer evaluation of project proposals is the importance of a clear contextual justification for the particular location and cultural context in which the creative work and related research activities are to be situated. This expectation is perhaps understandable given that it is broadly agreed in arts academia that a review of existing literature and related artistic exemplars helps a researcher demonstrate a project's genetic roots. It also enables the researcher to fine-tune the problem or question and provide some parameters for selecting appropriate research methodologies.

A lack of a clear and robust contextualizing framework in artistic research proposals is a relatively common criticism across Project

70 Peer Reviewer 19. "Evaluation of proposal 42" Project anywhere (internal documents), September 2013.

71 Ibid.

72 Peer Reviewer 24. "Evaluation of proposal 38" Project anywhere (internal documents), September 2013.
Anywhere's archive of evaluations. Peer Reviewer 19's evaluation of Proposal 42 for example, points out that the "the socio-political or historical/ecological context of [location removed] needs clarification in order to set the stage for this theoretical investigation to carry more cultural significance." ${ }^{70}$ This reviewer also sought further clarification as to whether "the project capitalize[s] on site-specific sourcing of materials or forms." ${ }^{" 71}$ More pointedly, Peer Reviewer 24's rejection of Proposal 38, stressed that "apart from the novelty value of addressing [location removed] as a context, it is difficult to see why this research methodology is not applied to social contexts [elsewhere] on the planet." 72 Similarly for Peer Reviewer 26, historical references in Proposal 45 needed "to be more clearly explained and integrated into the conceptual rational of this proposed project." ${ }^{73}$ By contrast, Peer Reviewer 22's favourable evaluation of Proposal 35 outlined "a clear and exciting relationship to existing knowledge about [detail removed] and more conceptually orientated subjects about [detail removed]." 74 Similarly, Peer Reviewer 25 saw Proposal 35 as substantially addressing the specific "nature of temporality, methodology and space $[. .$.$] in$ conjunction with the role of the artist." 75

It is generally held that a research method should be responsive to the research context, relevant and ethical, valid, applied consistently with discipline and care, documented, accessible, explicit and transparent. A common criticism of much contemporary art and research that embeds itself in specific cultural contexts (despite its often inclusive rhetoric) is that it serves the short-term interests of the artist/researcher rather than that of the specific community context into which it is inserted. Peer Reviewer 23's evaluation of Proposal 34 contended that if the researcher "wants to use public space as its context of presentation, and to bring non art-world publics to a consideration," that more inclusive contextualisation

73 Peer Reviewer 26. "Evaluation of proposal 45" Project anywhere (internal documents), September 2014.

74 Peer Reviewer 22. "Evaluation of proposal 35" Project anywhere (internal documents), September 2013. 75 Peer Reviewer 25 "Evaluation of proposal 35" Project anywhere (internal documents), September 2013. 
would be required, lest it "further mystify that to which it wishes to bring more transparency and access." ${ }^{76}$ Similarly, Peer Reviewer 26 thought that the Proposal 64 would be strengthened by organising a "workshop with the participants [toward] a better connection and understanding of the research and [provide] better feedback to the artist." 77

Some ethical concerns were more explicitly stated. Peer Reviewer 26's evaluation of Proposal 50 cautioned to be "mindful of exotifying Indigenous art and culture through a European lens," and moreover, that " $[t]$ here are very subtle and sophisticated debates about the difficulties Indigenous artists face”, and consequently, "[p]erhaps the artist should consider addressing the work of contemporary Indigenous artists first." ${ }^{\text {78 }}$ Meanwhile, Peer Reviewer 23 was concerned that although Proposal 42 "might engender new knowledge for the project creator and for participants" [it] will not produce any new knowledge widely accessible to a larger public", and consequently, had "a hint of academic remoteness about it" "79. In stark contrast, Peer Reviewer 25's evaluation of Proposal 43 applauded a rigorous "formal, sociological and phenomenological analysis of site" coupled with comprehensive "interviews with stakeholders" and the subsequent "development of strategies surrounding community engagement." ${ }^{80}$ Research proposals such as these closely resemble established multi-method and triangulated approaches to qualitative research, which can of course include diverse data collection methods.

An issue consistently raised by reviewers is the importance of a clear contextual framing within existing discourses and methodologies when working across disparate fields. This is

76 Peer Reviewer 23. "Evaluation of proposal 34" Project anywhere (internal documents), September 2013.

77 Peer Reviewer 26. "Evaluation of proposal 64" Project anywhere (internal documents), September 2014.

78 Peer Reviewer 26. "Evaluation of proposal 50" Project anywhere (internal documents), September 2014.

79 Peer Reviewer 23. "Evaluation of proposal 42" Project anywhere (internal documents), September 2013.

80 Peer Reviewer 25. "Evaluation of proposal 43" Project anywhere (internal documents), September 2013. invariably complicated, for artistic research can intersect fields as diverse as history, politics, philosophy, the social sciences, cultural studies, linguistics, the sciences, mathematics, geography, urban planning, architecture and so on. For many artist academics, the value of a project's contribution to the field of art is easily muddied once "dressed up" in the language of another discipline. Peer Reviewer 20's evaluation of Proposal 38 for example, stressed that although "a significant understanding of the science and technology" was demonstrated, less "attention [was] paid to [...] discourses relating to art." ${ }^{81}$ Similarly, Peer Reviewer 18's evaluation of Proposal 36 identified a lack of " artistic references." ${ }^{82}$ More pointedly, Peer Reviewer 21 argued that Proposal 36 was "not convincingly situate[d] within existing discourses of hybridity as they relate to artistic practice." 83

For Claire Bishop, a leading critic of "uncritical" social practice by artists, our acceptance that art cannot be quarantined from the influence of other fields has in turn provided artists with an opportunity for having their cake and eating it. For Bishop, a double disclaimer is then created in which artists can seek legitimacy outside of the art condition (i.e. in social value or "good politics") if required to defend their work within the art world, and conversely, revert to sounding "preposterously arty" if called upon to defend their work outside of the "art world." ${ }^{84}$ For Bishop, this occurs because many artistic projects now straddle a doubled ontological existence insofar that they are art and at the time something else (a public event, a scientific experiment, a design, a political protest, a social conversation etc.).

81 Peer Reviewer 20. "Evaluation of proposal 38" Project anywhere (internal documents), September 2013.

82 Peer Reviewer 18. "Evaluation of proposal 36" Project anywhere (internal documents), September 2013.

83 Project anywhere (internal documents),. Peer Reviewer 21. "Evaluation of proposal 36", September 2013.

84 BISHOP, C. "Participation and spectacle: where are we now?", lecture in conjunction with Living as form, Creative Time, 80 Essex St, New York, New York, September 23, 2011, http://vimeo.com/24193060 (retrieved 06/10/2014). 
It is broadly agreed that there are conceptual and methodological differences between creative research other forms of enquiry such as scientific research. For Dally et al., for example, "scientific methods, such as formulating hypotheses, pursuing solutions and reaching conclusions" might be effectively "incompatible with artistic practice." ${ }^{85}$ Accordingly, some peer reviewers were suspicious about the validity of scientific and other quantitative approaches imported into artistic research. In Peer Reviewer 23's evaluation of Proposal 38 it is noted that although the "project appears at first reading to be based in scientific research methods [it is not ] based in scientific research that would yield results." ${ }^{86}$ For Peer Reviewer 40 , Proposal 54 "refers to neurology [...] in a superficial manner." ${ }^{87}$ By stark contrast, Peer Reviewer 22 found Proposal 36 to be "deeply speculative, experimental and discursive in nature [creating] a useful discussion between science and art $[\ldots]$ that does not fall prey to overly literal natural science projects." $\$ 8$

Just as Michel Foucault famously contended that art is as valid as an independent form of knowledge without obeying the criteria of scientific methods, and that the appeal of artistic forms of knowledge is for some specifically located in art's seeming ability to traverse diverse forms of presentation in order to evoke other forms of knowledge, ${ }^{89}$ many peer reviewers stressed the value of maintaining the discursive and speculative qualities of artistic research. For Graeme Sullivan in 2010, the fact that art has a capacity to change artists' conceptions but also influence viewer interpretation implicates it

85 Dally, K., \& HOLBROOK, A., \& LAWRY, M., \& GRAHAM, A., "Assessing the exhibition and the exegesis in visual arts higher degrees: perspectives of examiners". Working papers in art and design 3, sitem.herts.ac.uk/artdes_research/papers/wpades/vol3/kdfull.html (retrieved 12/07/2014).

86 Peer Reviewer 23. "Evaluation of proposal 38" Project anywhere (internal documents), September 2013.

87 Peer Reviewer 40. "Evaluation of proposal 54" Project anywhere (internal documents), September 2014.

88 Peer Reviewer 22. "Evaluation of proposal 36" Project anywhere (internal documents), September 2013. as a form of inquiry sufficiently robust as to yield insights that are grounded and culturally relevant. ${ }^{90}$ As mentioned previously, research questions within artistic research projects often evolve or change during the study due to their focus upon exploring phenomena (this is of course also true of other forms of research). Although artistic research typically involves, as Brad Haseman and Daniel Mafe put it in 2009, "creative action and critical reflection" also "acknowledges and accommodates subjectivity, emotionality and the researcher's influence on research." ${ }^{91}$ Acknowledgement of this subjective dimension was clearly regarded as conspicuously lacking in Peer Reviewer 24's evaluation of Proposal 43:
Attempting to fit this project into a socially constructive or useful framework limits the poetic and experimental poten- tial of this project. The "data collection and analysis' portion of the methodology is too market research driven, and $[\ldots]$ places limitations on the conceptual development ${ }^{92}$

Unlike research methodologies where it is possible to formulate a precise question at the beginning and then measure the success of the study by how well the question has been answered at the end, transparent reflection upon process is a central feature within much artistic research (this is of course also true of some qualitative research methods). Unlike research in related fields such as design, whose raison d'être is typically more explicitly conceived to serve a specifically utilitarian outcome, proponents of research in which

89 See: BUSCH, K. "Artistic research and the poetics of knowledge" Art \& research: a journal of ideas, contexts and methods, Vol. 2 No. 2, Spring 2009. http://www.artandresearch.org.uk,v2n2,busch.html (retrieved 3/07/2014). 90 SULLIVAM, G. Art practice as research: inquiry in the visual arts, Thousand Oaks: Sage, 2010.

91 HASEMAN, B. \& MAFE, D. "Acquiring know-how: research training for practice-led researchers" in SMITH, $\mathrm{H}$ \& DEAN, R. Practice-led research, research-led practice in the creative arts, Edinburgh: Edinburgh University Press, 2009, p. 217.

92 Peer Reviewer 24. "Evaluation of proposal 43" Project anywhere (internal documents), September 2013. 
artistic practice is the significant medium routinely point to the value of art as a vehicle for unlocking insights and understandings potentially elusive in a theoretical, rational, philosophical or political propositions alone. As Paula Pogré recently put it, this means "thinking about art as a practice of knowledge and not simply as a utilitarian tool for understanding other fields." 93 This point of difference clearly breaks down wherever an artistic research project "lend[s] itself to didacticism" ${ }^{94}$ or forgets that art can "be political in ways other than just information giving" ${ }^{95}$, or on the other hand, "indulge[s]" in "aestheticizating [...] without reflection" upon accompanying "social symptoms." 96

\section{Conclusion}

The status of knowledge production in the creative arts remains a problematic issue for many reasons. Much debate still centres around the question as to whether knowledge is located in the art object/experience itself or rather built via the contextualising and paratextual support of exegetical and scholarly texts. This question in itself is of course a vital area of research. At any rate, research in which artistic practice is the significant medium is typically supported by variations of the epistemological premise that there are multiple ways of experiencing, knowing and communicating knowledges, and accordingly, that there is no single, correct or prescriptive way to experience or transmit and disseminate knowledge of that experience. This epistemological premise naturally makes it extremely difficult to establish consistent criteria for evaluation or appropriate guidelines for the dissemination of new knowledge presented within or alongside creative practice.
The field of artistic research is clearly a vast and contested arena that is characteristically resistant to (and on occasion actively hostile toward) the kinds of institutional categories that have historically underpinned museological organization and academic catagorization. Complicating this picture further, rather than simply generically defying museological organization and academic catagorization altogether, even the most "extreme" examples of what might meaningfully constitute artistic research exhibit at least some degree of a negotiation of medium specificity and intermedial expansion in order be even recognized as a category of "art". In a radically discursive and ever expanding field of production and enquiry, artistic practitioners overlay new context and potential onto new and pre-existing elements to produce dynamic constellations of signs, concepts, myths, traces, objects, data, locations, gestures, forms, sensations and contradictions intertwined in networks of collective interpretations which in turn extend across time and space via further iterations, documentations and discussions. As Luis Camnitzer recently put it: "Art is not situated in between; it is the umbrella that hovers over everything and includes everything." ${ }^{97}$ For Camnitzer, this "inclusiveness makes art a meta-discipline, with science as one of its many subcategories" ${ }^{98}$. This radical discursiveness ultimately means that the challenge of translating the kinds of knowledge production which emanate from creative processes into formats commensurate with the journal based paradigm for evaluating the quality of research outcomes-and at the same time maintaining relatively stable conditions for dialogue and critical reflection-is bound to be a mixed enterprise.
93 Paula Pogré, "Art: a form of knowledge and understanding" Who and what is arts education for? Debate moderated by CAMNITZER, L. September 2, 2014, Colección Patricia Phelps de Cisneros, http://www.coleccioncisneros.org/ node/413 (retrieved 3/07/2014).

94 Peer Reviewer 26. "Evaluation of proposal 57" Project anywhere (internal documents), September 2014.

95 Ibid.
96 Peer Reviewer 40. "Evaluation of proposal 53" Project anywhere (internal documents), September 2014.

97 CAMNITZER, L. "An artist, a leader, and a dean were on a boat..." e-flux Journal \#55, May 2014, http://www.e-flux. com/journal/an-artist-a-leader-and-a-dean-were-on-a-boat... retrieved 3/10/2014). 98 Ibid. 
Given the inextricable challenges of establishing relatively stable conditions for the evaluation and dissemination for artistic research whilst maintaining an accountable level of scholarly rigor, the evaluation criteria established by Project Anywhere are designed to balance a radical openness to the unknowable nature and future possibilities of "art" with a commitment to conform to definitions and expectations of rigor and clarity which are institutionally demanded of "research"

By accepting that research "is defined as the creation of new knowledge and/or the application of existing knowledge so as to generate new concepts, methodologies and understandings," and that artistic research must therefore make "a clear and compelling claim for the project's potential to contribute to knowledge" 99 Project Anywhere has clearly decided how it wishes to delineate artistic research. Declaring a preference for championing institutional definitions of research is bound to invite dissent from some artists. For some dissenters, art has only been reconfigured as research in order to meet the demands of the knowledge economy. This shift has meant that artists are now routinely expected to be versed in discourses previously unimagined by those that saw art as a refuge from institutional conformity and conventional forms of language.

Given that a creative work is always in formation, it is potentially counterproductive to either nail it down too prescriptively or early in the process of formation through conventional language. Somehow, the role of ambiguity must be acknowledged and managed appropriately throughout the process of generating artistic research. Otherwise, artists end up working within implausible frameworks or toward ends that serve fields with little appreciation of art's raison d'être.

99 "Evaluation criteria" Project anywhere: art at the outermost limits of location-specificity, http://www.projectanywhere. net/peer-review/ (retrieved 06/10/2014).

100 SNOW, C. P. The two cultures. London: Cambridge University Press, 2001, p. 3.
Perhaps the biggest divide between artistic research and the world of "proper research" still boils down to the inconvertible distance between the sciences and the arts famously expressed by C. P. Snow in $1959 .{ }^{100}$ Perhaps we should keep remembering to ask ourselves: what do we really mean by and how do we express understanding? Is experiencing an idea a form of understanding? Understanding of research in which artistic practice is the significant medium clearly involves both experience and explanation. But there is clearly no prescription or formula for consistently accounting for how experience and explanation should work together. It is therefore vitally important that the introduction of evaluative frameworks does not expunge the experiential value of contradiction and ambiguity from the whole process. It is for this reason, despite the fact that Project Anywhere's evaluation criteria insists that a proposal make "a clear and compelling claim for the project's potential to contribute to knowledge in an identified field of creative practice", that it also notes the project can "be speculative, experimental or discursive in nature." ${ }^{101}$ It is also why, despite stressing that a "claim should be made in the form of a hypothesis or proposition and it should identify relevant literature and aligned creative work," that it may nonetheless "extend or contradict existing methodologies.” 102

Ultimately, researched references cannot wholly "explain" or directly "inform" a creative work. Instead, relevant literature and creative exemplars might meaningfully place a work within a wider context or field. It remains important to concede that something is always lost and/or gained in any translation into words. Yet at the same time, it is important to acknowledge that an artist is not an emotively fuelled mythical figure existing in a fictional world beyond language. Although participating in research culture has become essential for artists wishing to stake a claim

101 "Evaluation criteria" Project anywhere: art at the outermost limits of location-specificity, http://www.projectanywhere. net/peer-review/ (retrieved 06/10/2014). 102 Ibid. 
in a knowledge-based economy, it is also important to remain mindful of the key points that might differentiate art, and by extension, artistic research. Why, and for whom, are we undertaking these activities? As Geczy saliently warns, in a campaign to seek parity with "traditional research models", art "runs the risk of escaping itself." ${ }^{103}$ Perhaps, as Geczy puts it "the reward for compromise is so far only the prize for second place." 104

As is argued in this paper, the already complex challenges facing artistic research are further exacerbated by the movement of much art and related research activity beyond the confines of traditional exhibition spaces such as museums and galleries and into an ever expanding field of practice at "the outermost limits of location-specificity." ${ }^{105}$ From other trailblazing initiatives, such as The Journal for Artistic Research (JAR), The Center for Land Use Interpretation (CLUI), N55 and The Found Initiative, through to the subject of this paper, Project Anywhere, this discursive and interdisciplinary intersection of art and research with the frontiers of site, space, place, time, the virtual and the social is being meaningfully engaged on many fronts. Project Anywhere represents a small but vital part of this complex and ongoing process of generating appropriate new democratic models for the evaluation and dissemination of art and research outside traditional exhibition environments.

103 GECZY, A. "The new textuality for the visual arts: entrenchment in the academy, Broadsheet: contemporary visual art + culture, vol. 43.3, 2014, p. 71 .

104 Ibid.
105 Project anywhere: art at the outermost limits of location-specificity, http://projectanywhere.net (retrieved 06/10/2014). 


\section{Project Anywhere: le défi d'évaluer et de disséminer l'art et la recherche artistique en dehors des environnements traditionnels d'exposition}

Les défis auxquels font face les artistes qui cherchent à produire, à valider et à disséminer l'art et la recherche artistique en dehors des lieux traditionnels d'exposition sont variés et complexes. Cet article examine les problèmes principaux que rencontrent les artistes qui œuvrent hors des environnements traditionnels que sont les galeries et les musées. Établi en 2012, Project Anywhere a été conçu en tant que solution possible. Il s'agit d'un modèle d'exposition élargi qui prend en compte le globe entier, et où le rôle de commissaire est remplacé par un modèle d'évaluation par les pairs semblable à celui de la publication scientifique. Pointant spécifiquement sur l'activité artistique et la recherche entreprises en dehors des musées et des galeries d'exposition, ce projet est dédié à l'évaluation et la dissémination de l'art aux extrêmes limites de la spécificité du lieu par un processus d'évaluation à l'aveugle qui permet de déterminer la qualité de l'issue de la recherche artistique.Cet article analyse le fonctionnement et les limites du modèle de la double évaluation à l'aveugle du Project Anywhere. Faisant référence aux documents internes accumulés par les pairs évaluateurs du projet (tous des artistes reconnus internationalement et issus du milieu universitaire) invités à évaluer les propositions d'un programme global d'exposition annuelle, l'article traite du problème de bien identifier et qualifier les possibilités de produire des connaissances en recherche artistique discursive qui soient à la hauteur des critères de clarté et de pertinence de la recherche traditionnelle. En défiant les suppositions épistémologiques classiques, les deux dernières décennies ont été témoins d'une volonté accrue de reconnaître la recherche qui implique la production artistique en tant que paradigme légitime au même titre que les approches qualitatives et quantitatives. Par ailleurs, l'intégration de plus en plus courante des écoles d'art au sein des universités appelle les artistes du milieu universitaire à réviser leur travail créatif en termes savants. Même s'il existe une reconnaissance institutionnelle qui soutient que, dans certains cas, l'art " parle par lui-même " et que la production d'un savoir nouveau est générée par la matérialité de l'œuvre elle-même, il existe un consensus plus large qui stipule que la production d'objets créatifs ou de processus en tant qu'efforts de recherche devrait être accompagnée d'un texte exégétique ou d'une mise en contexte théorique. Il faut toutefois considérer un aspect important de la recherche où la pratique artistique constitue le principal médium, celui de la valeur des idées qui émergent par le biais des processus de fabrication et de réalisation.Puisque les artistes se sont été intégrés aux universités depuis plusieurs décennies, cet article considère que le défi posé par la validation institutionnelle de la recherche entreprise par les artistes demeure irrésolu. Cet état velléitaire est exacerbé par l'expansion infinie de l'art et de la recherche hors des espaces traditionnels d'exposition tels que les musées et les galeries. L'article considère que même s'il y a un manque réel de consensus quant aux terminologies clés et de nombreux débats relatifs à ce que ce type de recherche entraîne, une convergence émerge en ce qui a trait aux 
définitions de base. Même si la recherche entreprise par les artistes est de bien des façons comparable à toute autre recherche, la transférabilité des savoirs générés par le processus de recherche demeure irrésolue. Cet article démontre que le statut de la production de savoirs dans le champ des arts créatifs demeure problématique, pour de nombreuses raisons. Sans doute que les discours inhérents aux arts créatifs imposent l'idée qu'une traduction significative de la production de savoirs émanant des processus créatifs vers les modèles établis des publications scientifiques est une entreprise complexe. 